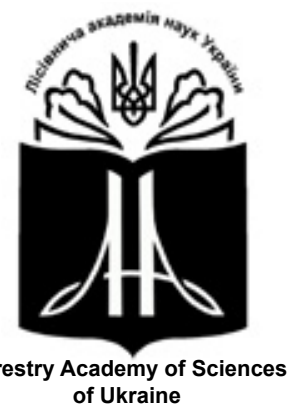

Наукові праці Лісівничої академії наук України Proceedings of the Forestry Academy of Sciences of Ukraine

http://fasu.nltu.edu.ua https://doi.org/10.15421/411908

Article received 2018.10.12

Article accepted 2019.03.28
ISSN 1991-606X print

ISSN 2616-5015 online

@ $₫$ Correspondence author

Rimma Matveeva

selekcia@sibgtu.ru

peace Avenue, 82, Krasnoyarsk, 660049, Russia

УДК $630 * 181.52$

\title{
Рост 50-летних подпологовых географических культур кедра сибирского при разной сомкнутости полога древостоя в пригородной зоне Красноярска
}

\author{
Р.Н. Матвеева' ${ }^{1}$ О.Ф. Буторова², Э. В. Колосовский
}

Кедр сибирский, отличаюшийся иенными биоэкологическими свойствами, является одной из лесообразующих пород Сибири. Учитьввая больщую устойчивость кедра сибирского при произрастании в биогруппах, под руководством О.П. Олисовой были созданы подпологовые географические культуры кедра сибирского на участке «Горный-2» весной 1966 г. посадкой 4-летних сеянцев в площадки размером 07 × 0,7 м (по 9 сеянцев в площадку). Расстояние между иентрами площадок составило 4 м.

Обобщены результаты изучения изменчивости таксационных показателей кедра сибирского шести географических происхождений: алтайское, бирюсинское, бурятское, кемеровское, томское, читинское, произрастающих под пологом березы повислой и сосны обыкновенной при сомкнутости полога древостоя от 0,1 до 1,0. Установлено, что в 50-летнем возрасте культуры кедра сибирского достигли высоты 5,4-10,4 м, диметра ствола - 5,2-11,5 см. Культуры, произрастающие при сомкнутости полога 0, 1-0,5, имели высотуна 36,6\%, диаметр ствола - на 44,8\% больше, чем при сомкнутости 0,6-1,0. Уровень изменчивости показателей-средний и высокий. Наибольшее количество ветвей в нижней живой мутовке (4,8 и 4,1 шт.) зафиксировано у деревьев читинского, наименьщее (3,2 и 2,3 шт.) - у деревьев кемеровского происхождений. Уровень варьирования показателя повышенный - в алтайском, бирюсинском вариантах; выссокий - в остальных при меньшей сомкнутости полога. При сомкнутости полога 0,6-1,0 уровень изменчивости повышенный и высокий (26,5-41,9\%).

Установлено, что большое влияние на биометрические показатели культур оказывает сомкнутость полога $(65,0 \%)$. Доля влияния географического происхождения составила 13,8\%. Предложено проведение рубок ухода для снижения сомкнутости полога древостоя.

Ключевые слова: лесные культуры; географическое происхождение; густота; изменчивость; биолетрические показатели; Сибирь.

Введение. Кедр сибирский или сосна кедровая сибирская (Pinus sibirica Du Tour) является уникальной лесообразующей породой Сибири, высоко ценится в лесоводственном и экологическом аспектах. Учитывая повышенную фитонцидность кедровых насаждений, рекомендуется сохране- ние и создание лесных культур данного вида в пригородных зонах промышленных центров Сибири (Protopopov, 1975).

Создание культур кедра сибирского проводится как в условиях естественного ареала, так и за его пределами (Drozdov et al., 1978, 2013, Titov,

Матвеева Римма Никитична - доктор сельскохозяйственных наук, профессор кафедры селекции и озеленения. Сибирский государственный университет науки и технологий имени академика М.Ф. Решетнева, пр. Мира, 82, г. Красноярск, 660049, Россия. Тел.: (391)227-58-09. E-mail: selekcia@ sibgtu.ru ORCID: https://orcid.org/0000-0002-3476-9622

2 Буторова Ольга Федоровна - доктор сельскохозяйственных наук, профессор кафедры селекции и озеленения. Сибирский государственный университет науки и технологий имени академика М.Ф. Решетнева, пр. Мира, 82, г. Красноярск, 660049, Россия. Тел.: (391)227-58-09. E-mail: selekcia@ sibgtu.ru ORCID: https://orcid.org/0000-0001-8575-7464

3 Колосовский Эдуард Викторович - аспирант кафедры селекции и озеленения. Сибирский государственный университет науки и технологий имени академика М.Ф. Решетнева, пр. Мира, 82, г. Красноярск, 660049, Россия. Тел.: (391)227-58-09. E-mail: selekcia@ sibgtu.ru 
1990, 2016, Kuznetsova, 1990, 2010, Bryncev \& Kozhenkova, 2016, Zemljanoi et al., 2010, Bratilova, 2005, 2015 et al.). Однако некоторые вопросы лесокультурного производства данного вида остаются нерешенными, что связано с продолжительным периодом онтогенеза, замедленным проявлением хозяйственно-ценных признаков, различным географическим происхождением (Bratilova et al., 2005, Von Mirko Liesebach et al., 2008, Kuznetsova, 2010, Matveeva, Bratilova \& Butorova, 2017 et al.).

Большое влияние на рост культур данного вида оказывают условия произрастания, в частности, сомкнутость полога древостоя. Необходимость учета влияния данного фактора на продуктивность насаждений отмечал Anuchin (1983). Особенности роста подпологовых культур кедра сибирского показаны также в ряде научных работ (Babakin \& Zolotukhin, 1976, Zalesov, 1988, Ermolenko \& Ovchinnikova, 1996 et al.).

Учитывая большую устойчивость кедра сибирского при произрастании в биогруппах, особенно в первые годы жизни, в Сибири в каждое посадочное место высаживали по 4-16 сеянцев (Loskutov, 1971). Eremin, Karaseva \& Karasev (2010) также отмечали высокую сохранность культур кедра сибирского, созданных биогруппами с применением гнездового способа посадки в условиях Республики Марий Эл.
Целью исследований явилось установление влияния сомкнутости полога древостоя на интенсивность роста 50-летних культур кедра сибирского разного географического происхождения, проявление индивидуальной изменчивости деревьев, произрастающих под пологом леса.

Объекты и методика исследований. Объектом исследований явились географические подпологовые культуры кедра сибирского на участке «Горный-2» в пригородной зоне Красноярска. Лесные культуры на этом участке были созданы весной 1966 г. под руководством доцента кафедры лесных культур Сибирского технологического института (в настоящее время - СибГУ им. М.Ф. Решетнева) Ольги Павловны Олисовой.

Посадка проведена в площадки размером $0,7 \times$ 0,7 м. Расстояние между центрами площадок составляло 4 м, в каждую площадку было высажено по 9 сеянцев. Для создания культур использовали 4-летние сеянцы шести географических происхождений: алтайское, бирюсинское, бурятское, кемеровское, томское, читинское. Секции каждого географического происхождения включали по 80 площадок из 720 растений.

Характеристика места произрастания материнских насаждений на период сбора семян для создания культур приведена в табл. 1.

Таблица 1

\section{Характеристика материнских насаждений, использованных для сбора семян} и выращивания посадочного материала

\begin{tabular}{|c|c|c|c|c|c|c|c|}
\hline \multirow{2}{*}{$\begin{array}{c}\text { Географическое } \\
\text { происхождение: лесничество, } \\
\text { республика (край, область) }\end{array}$} & \multicolumn{2}{|c|}{ Координаты } & \multirow{2}{*}{$\begin{array}{l}\text { Высота } \\
\text { над ур. } \\
\text { моря, м }\end{array}$} & \multicolumn{2}{|c|}{ Класс } & \multirow{2}{*}{$\begin{array}{l}\text { Тип } \\
\text { леса }\end{array}$} & \multirow{2}{*}{$\begin{array}{c}\text { Состав } \\
\text { древостоя }\end{array}$} \\
\hline & с.ш. & в.д. & & бонитета & возраста & & \\
\hline Бирюсинское, Красноярский & $56^{\circ}$ & $92^{\circ}$ & 300 & III & $\mathrm{V}$ & Крт & 7К2Е1П \\
\hline Красно-Чикойское, Забайкальский & $50^{\circ}$ & $108^{\circ}$ & 700 & IV & VII & Крт & $6 \mathrm{~K} 4 \mathrm{C}$ \\
\hline Мариинское, Кемеровская & $56^{\circ}$ & $87^{\circ}$ & 500 & III & IV & Кзмш & $7 К 2 П 1 Б$ \\
\hline Селенгинское, Бурятия & $50^{\circ}$ & $106^{\circ}$ & 1000 & IV & $\mathrm{V}$ & Кбр & $6 К 3 С 1$ Л \\
\hline Томское, Томская & $56^{\circ}$ & $84^{\circ}$ & 100 & II & VI & Крт & 8 К1Е1П \\
\hline Чойское, Алтай & $51^{\circ}$ & $86^{\circ}$ & 500 & III & VI & Крт & 6КЗП1Б \\
\hline
\end{tabular}

Примечание: Крт - кедрач разнотравный, Кзмш - кедрач зеленомошный, Кбр - кедрач брусничный

В настоящее время географические культуры произрастают под пологом насаждения, состоящего из березы повислой и сосны обыкновенной (рис. 1). Сомкнутость полога древостоя над площадками составляет от 0,1 до 1,0 .

Программа исследований включала сопоставление биометрических показателей кедра сибирского в подпологовых культурах в зависимости от географического происхождения и сомкнутости полога древостоя.

У лидирующих в каждой площадке деревьев (рис. 2) определяли высоту, диаметр ствола на высоте 1,3 м, диаметр кроны, высотный прирост центрального побега, длину и количество боковых ветвей на нижней живой мутовке и др.
Статистическую обработку данных проводили по общепринятой методике (Dospehov, 1979). Уровень изменчивости показателей оценивали по шкале, предложенной С.А. Мамаевым (Mamaev, 1973).

Достоверность различий определяли по t-критерию. Устанавливали наличие и тесноту связи между изучаемыми показателями. Долю влияния географического происхождения и сомкнутости полога на показатели культур устанавливали методом дисперсионного анализа.

Результаты исследований. Проведено сравнение интенсивности роста кедра сибирского в 50 -летних культурах при низкой $(0,1-0,5)$ и высокой $(0,6-1,0)$ сомкнутости полога древостоя (табл. 2). 


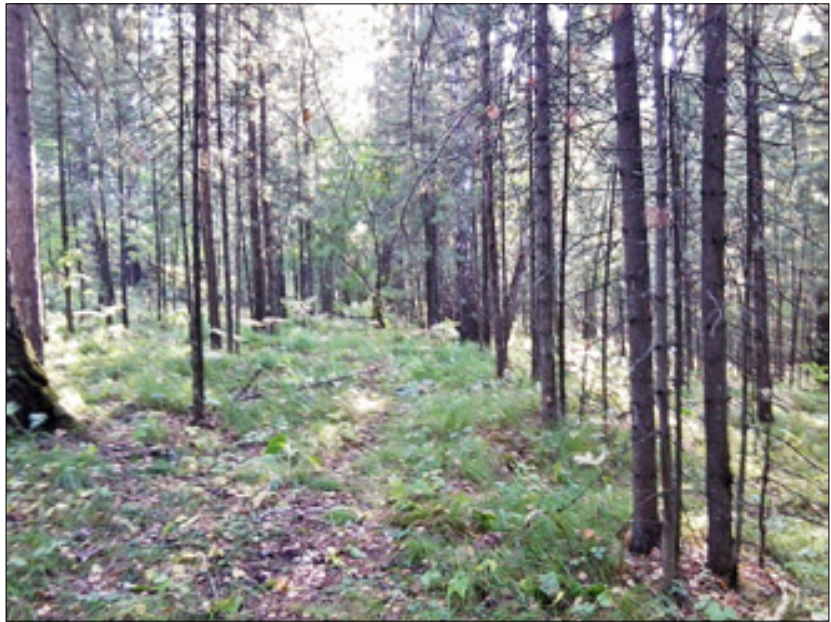

Рис. 1. Общий вид исследуемого участка

Средняя высота культур при меньшей сомкнутости полога древостоя составляет 9,7 м, при высокой сомкнутости она на $36,6 \%$ ниже. Уменьшение высоты при сомкнутости полога 0,6-1,0 отмечено в вариантах всех сравниваемых про- исхождений. При сомкнутости полога 0,1-0,5 наибольшая высота была у деревьев читинского, при сомкнутости 0,6-1,0 - алтайского происхождений.

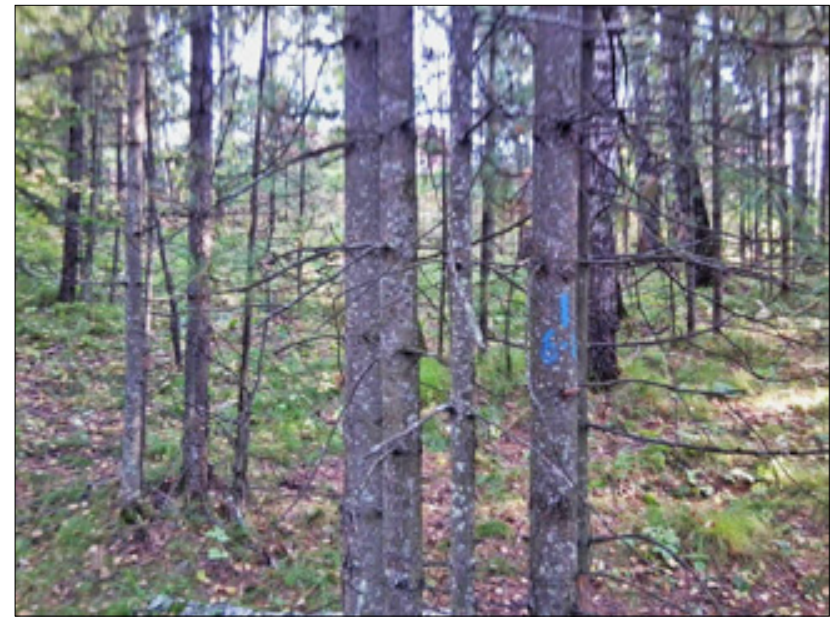

Рис. 2. В каждой площадке выделены лидирующие деревья кедра сибирского

Таблииа 2

\section{Высота 50-летних культур кедра сибирского при разной сомкнутости полога, м}

\begin{tabular}{|c|c|c|c|c|c|c|c|c|}
\hline $\begin{array}{l}\text { Географическое } \\
\text { происхождение }\end{array}$ & $\max$ & $\min$ & $\mathrm{X}_{\mathrm{cp}}$ & $\pm \mathrm{m}$ & $\mathrm{V}, \%$ & $\mathrm{P}, \%$ & $\begin{array}{c}\mathrm{t}_{\phi} \text { при } \\
\mathrm{t}_{05}=2,00\end{array}$ & $\begin{array}{c}\text { Уровень } \\
\text { изменчивости }\end{array}$ \\
\hline \multicolumn{9}{|c|}{ При сомкнутости полога 0,1-0,5 } \\
\hline Алтайское & 14,0 & 5,0 & 9,9 & 0,35 & 20,8 & 3,5 & 1,19 & повышенный \\
\hline Бирюсинское & 13,5 & 6,2 & 9,1 & 0,29 & 18,6 & 3,2 & 3,51 & средний \\
\hline Бурятское & 14,2 & 5,1 & 9,7 & 0,40 & 18,9 & 4,1 & 1,52 & средний \\
\hline Кемеровское & 13,6 & 5,0 & 9,0 & 0,44 & 23,3 & 4,8 & 2,82 & повышенный \\
\hline Томское & 14,3 & 6,8 & 10,2 & 0,31 & 16,6 & 3,0 & 0,52 & средний \\
\hline Читинское & 13,2 & 6,0 & 10,4 & 0,23 & 14,3 & 2,2 & - & средний \\
\hline Среднее значение & & & 9,7 & & & & & \\
\hline \multicolumn{9}{|c|}{ При сомкнутости полога 0,6-1,0 } \\
\hline Алтайское & 13,5 & 4,2 & 9,2 & 0,39 & 26,0 & 4,3 & - & повышенный \\
\hline Бирюсинское & 9,0 & 3,0 & 6,1 & 0,23 & 24,7 & 3,7 & 6,85 & повышенный \\
\hline Бурятское & 11,7 & 1,8 & 7,2 & 0,21 & 22,4 & 2,9 & 4,52 & повышенный \\
\hline Кемеровское & 8,5 & 2,0 & 5,4 & 0,21 & 27,6 & 3,8 & 8,58 & повышенный \\
\hline Томское & 10,3 & 2,1 & 7,2 & 0,24 & 22,7 & 3,3 & 4,37 & повышенный \\
\hline Читинское & 9,9 & 3,3 & 7,6 & 0,35 & 23,9 & 4,6 & 3,05 & повышенный \\
\hline Среднее значение & & & 7,1 & & & & & \\
\hline
\end{tabular}

Поскольку годичный прирост деревьев изменяется в очень больших пределах в зависимости от освещенности, погодных условий и других факторов (Salminen, \& Jalkanen, 2005, Demakov, \& Safin, 2010), проведено сравнение прироста побега за двухлетний период (в возрасте 49 и 50 лет) (табл. 3).

Прирост побега за два года в культурах с большим освещением в среднем составил 53,2 см, что на 41,1\% превышает данный показатель у кедра сибирского, произрастающего в затененных усло- виях при повышенном, высоком и очень высоком уровнях изменчивости. В исследуемых условиях наибольший прирост имели деревья читинского (сомкнутость полога $0,1-0,5)$ и алтайского (сомкнутость полога 0,6-1,0) происхождений (рис. 3).

Диаметр ствола деревьев в 50-летних культурах варьировал от 2,0 до 16,5 см. При наибольшем освещении средний диаметр составил 9,7 см, при большей сомкнутости полога - всего 6,7 см. Различие составляет $44,8 \%$ (табл. 4 ). 
Таблица 3

Прирост по высоте за два года у кедра сибирского в географических культурах при разной сомкнутости полога древостоя, см

\begin{tabular}{|c|c|c|c|c|c|c|c|}
\hline $\begin{array}{l}\text { Географическое } \\
\text { происхождение }\end{array}$ & $\max$ & $\min$ & Xсp. & $\pm \mathrm{m}$ & $\mathrm{V}, \%$ & $\mathrm{P}, \%$ & $\begin{array}{c}t_{\phi} \text { прии } \\
t_{05}=2,00\end{array}$ \\
\hline \multicolumn{8}{|c|}{ При сомкнутости 0,1-0,5 } \\
\hline Алтайское & 90 & 10 & 50,3 & 3,42 & 40,3 & 6,8 & 2,50 \\
\hline Бирюсинское & 75 & 18 & 39,8 & 2,12 & 30,6 & 5,3 & 6,67 \\
\hline Бурятское & 85 & 35 & 54,8 & 3,17 & 26,5 & 5,8 & 1,48 \\
\hline Кемеровское & 85 & 36 & 58,0 & 2,83 & 22,4 & 4,9 & 0,71 \\
\hline Томское & 80 & 30 & 55,8 & 2,36 & 23,2 & 4,2 & 1,46 \\
\hline Читинское & 95 & 25 & 60,6 & 2,29 & 24,2 & 3,8 & - \\
\hline Среднее значение & & & 53,2 & & & & \\
\hline \multicolumn{8}{|c|}{ При сомкнутости 0,6-1,0 } \\
\hline Алтайское & 85 & 5 & 47,7 & 3,40 & 43,4 & 7,1 & - \\
\hline Бирюсинское & 55 & 9 & 26,6 & 1,52 & 38,2 & 5,7 & 5,66 \\
\hline Бурятское & 80 & 10 & 39,2 & 1,68 & 33,0 & 4,3 & 2,24 \\
\hline Кемеровское & 70 & 5 & 35,4 & 2,06 & 39,9 & 5,8 & 3,09 \\
\hline Томское & 55 & 10 & 33,9 & 1,81 & 36,2 & 5,3 & 3,58 \\
\hline Читинское & 60 & 20 & 43,4 & 2,30 & 27,5 & 5,3 & 1,05 \\
\hline Среднее значение & & & 37,7 & & & & \\
\hline
\end{tabular}

Диаметр ствола деревьев при разной сомкнутости полога древостоя, см

\begin{tabular}{|c|c|c|c|c|c|c|c|}
\hline $\begin{array}{l}\text { Географическое } \\
\text { происхождение }\end{array}$ & $\max$ & $\min$ & Xcp. & $\pm \mathrm{m}$ & $\mathrm{V}, \%$ & $\mathrm{P}, \%$ & $\begin{array}{c}\mathrm{t}_{\phi} \text { при } \\
\mathrm{t}_{05}=2,00\end{array}$ \\
\hline \multicolumn{8}{|c|}{ При сомкнутости 0,1-0,5 } \\
\hline Алтайское & 16,5 & 5,0 & 9,5 & 0,42 & 26,3 & 4,5 & 3,92 \\
\hline Бирюсинское & 14,0 & 5,0 & 8,8 & 0,32 & 20,7 & 3,6 & 6,25 \\
\hline Бурятское & 13,1 & 7,5 & 10,0 & 0,31 & 14,0 & 3,1 & 3,53 \\
\hline Кемеровское & 14,0 & 5,0 & 8,8 & 0,40 & 21,6 & 4,5 & 5,46 \\
\hline Томское & 13,4 & 5,9 & 9,5 & 0,32 & 18,4 & 3,4 & 4,63 \\
\hline Читинское & 14,7 & 8,3 & 11,5 & 0,29 & 16,0 & 2,5 & - \\
\hline Среднее значение & & & 9,7 & & & & \\
\hline \multicolumn{8}{|c|}{ При сомкнутости 0,6-1,0 } \\
\hline Алтайское & 14,0 & 4,0 & 8,6 & 0,41 & 29,4 & 4,8 & - \\
\hline Бирюсинское & 9,0 & 2,0 & 5,8 & 0,22 & 25,2 & 3,8 & 6,02 \\
\hline Бурятское & 10,0 & 2,0 & 6,8 & 0,19 & 21,6 & 2,8 & 3,98 \\
\hline Кемеровское & 8,3 & 3,3 & 5,2 & 0,20 & 27,9 & 3,8 & 7,45 \\
\hline Томское & 9,8 & 2,4 & 6,2 & 0,21 & 22,6 & 3,3 & 5,21 \\
\hline Читинское & 10,3 & 3,4 & 7,6 & 0,35 & 23,8 & 4,6 & 1,86 \\
\hline Среднее значение & & & 6,7 & & & & \\
\hline
\end{tabular}

При лучшем освещении наиболее интенсивный рост по диаметру ствола наблюдается в культурах читинского происхождения (рис. 4).

Диаметр кроны деревьев на опытном участке составил в среднем 2,8 м при большей освещенности и 2,3 м - при меньшей (табл. 5).

Наибольший диаметр кроны зафиксирован у деревьев читинского, бурятского и томского происхождений при меньшей сомкнутости полога и читинского, алтайского - при большей. Уровень изменчивости показателя при большем освещении низкий и средний, при повышенном затенении средний и повышенный.

Количество боковых ветвей на нижней мутовке в среднем по вариантам опыта составило 4,3 шт. при большей освещенности, и 3,7 шт. - при меньшей (табл. 6). 


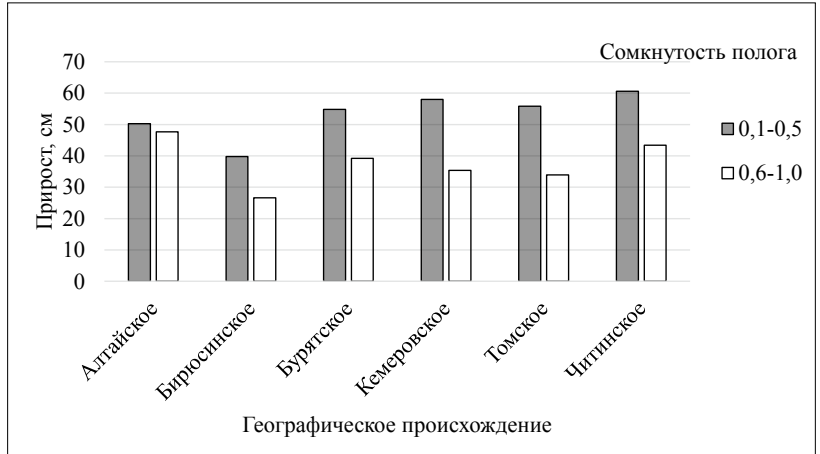

Рис. 3. Прирост по высоте центрального побега за два года в географических культурах при разной сомкнутости полога древостоя

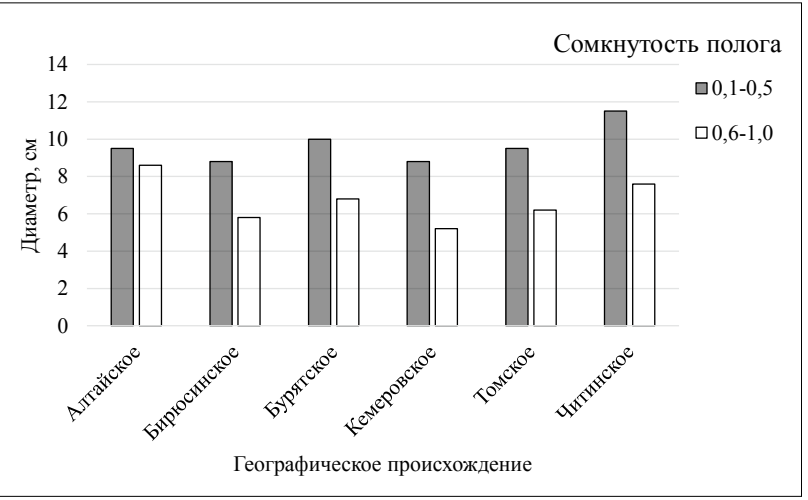

Рис. 4. Диаметр ствола кедра сибирского при сомкнутости полога древостоя 0,1-0,5 и 0,6-1,0

Диаметр кроны при разной сомкнутости полога древостоя, м

\begin{tabular}{|c|c|c|c|c|c|c|c|}
\hline $\begin{array}{l}\text { Географическое } \\
\text { происхождение }\end{array}$ & $\max$ & $\min$ & Xcp. & $\pm \mathrm{m}$ & $\mathrm{V}, \%$ & $\mathrm{P}, \%$ & $\begin{array}{c}\mathrm{t}_{\text {中 }} \text { при } \\
\mathrm{t}_{05}=2,00 \\
\end{array}$ \\
\hline \multicolumn{8}{|c|}{ При сомкнутости 0,1-0,5 } \\
\hline Алтайское & 3,8 & 1,8 & 2,6 & 0,08 & 18,0 & 3,0 & 4,00 \\
\hline Бирюсинское & 4,0 & 2,1 & 2,8 & 0,07 & 14,8 & 2,6 & 2,17 \\
\hline Бурятское & 3,6 & 2,3 & 2,9 & 0,07 & 11,8 & 2,6 & 1,08 \\
\hline Кемеровское & 3,4 & 2,0 & 2,8 & 0,07 & 12,4 & 2,6 & 2,17 \\
\hline Томское & 3,6 & 2,1 & 2,9 & 0,06 & 12,3 & 2,2 & 1,18 \\
\hline Читинское & 4,0 & 2,3 & 3,0 & 0,06 & 13,2 & 2,1 & - \\
\hline Среднее значение & & & 2,8 & & & & \\
\hline \multicolumn{8}{|c|}{ При сомкнутости $0,6-1,0$} \\
\hline Алтайское & 3,5 & 1,4 & 2,5 & 0,08 & 19,4 & 3,2 & - \\
\hline Бирюсинское & 3,0 & 0,4 & 2,1 & 0,07 & 22,8 & 3,4 & 3,76 \\
\hline Бурятское & 3,4 & 1,0 & 2,3 & 0,06 & 20,6 & 2,7 & 2,00 \\
\hline Кемеровское & 3,0 & 1,0 & 2,2 & 0,06 & 20,7 & 2,8 & 2,99 \\
\hline Томское & 3,3 & 1,4 & 2,3 & 0,06 & 16,2 & 2,4 & 2,00 \\
\hline Читинское & 3,1 & 1,7 & 2,4 & 0,07 & 15,1 & 2,9 & 0,94 \\
\hline Среднее значение & & & 2,3 & & & & \\
\hline
\end{tabular}

Таблииа 6

Количество ветвей в нижней живой мутовке при разной сомкнутости полога древостоя, шт.

\begin{tabular}{|c|c|c|c|c|c|c|c|}
\hline $\begin{array}{l}\text { Географическое } \\
\text { происхождение }\end{array}$ & $\max$ & $\min$ & Xсp. & $\pm \mathrm{m}$ & $\mathrm{V}, \%$ & $\mathrm{P}, \%$ & $\begin{array}{c}\mathrm{t}_{\phi} \text { при } \\
\mathrm{t}_{05}=2,00\end{array}$ \\
\hline 1 & 2 & 3 & 4 & 5 & 6 & 7 & 8 \\
\hline \multicolumn{8}{|c|}{ При сомкнутости 0,1-0,5 } \\
\hline Алтайское & 8 & 3 & 4,6 & 0,22 & 28,7 & 4,9 & 0,56 \\
\hline Бирюсинское & 7 & 2 & 4,2 & 0,21 & 28,3 & 4,9 & 1,71 \\
\hline Бурятское & 7 & 2 & 4,1 & 0,30 & 32,6 & 7,1 & 1,72 \\
\hline Кемеровское & 5 & 1 & 3,2 & 0,21 & 31,0 & 6,5 & 4,57 \\
\hline Томское & 8 & 1 & 3,9 & 0,23 & 33,1 & 6,0 & 2,48 \\
\hline Читинское & 10 & 1 & 4,8 & 0,28 & 38,1 & 6,0 & - \\
\hline Среднее значение & & & 4,3 & & & & \\
\hline \multicolumn{8}{|c|}{ При сомкнутости 0,6-1,0 } \\
\hline Алтайское & 8 & 2 & 4,1 & 0,20 & 30,2 & 5,0 & - \\
\hline
\end{tabular}


Продолжение таблиць 6

\begin{tabular}{lllccccc}
\hline \multicolumn{1}{c}{1} & 2 & 3 & 4 & 5 & 6 & 7 & 8 \\
\hline Бирюсинское & 5 & 1 & 3,2 & 0,17 & 35,1 & 5,2 & 3,43 \\
Бурятское & 7 & 1 & 3,9 & 0,18 & 35,8 & 4,7 & 0,74 \\
Кемеровское & 5 & 1 & 2,3 & 0,13 & 41,9 & 5,8 & 7,55 \\
Томское & 6 & 2 & 3,9 & 0,15 & 26,5 & 3,9 & 0,80 \\
Читинское & 5 & 1 & 4,0 & 0,26 & 35,2 & 6,8 & 0,30 \\
Среднее значение & & & 3,7 & & & & \\
\hline
\end{tabular}

Наибольшее количество ветвей в нижней живой мутовке $(4,8$ и 4,0 шт.) обнаружено у деревьев читинского происхождения, наименьшее $(3,2$ и 2,3 шт.) - у деревьев кемеровского происхождения. Уровень варьирования показателя повышенный - в алтайском, бирюсинском вариантах; высокий - в остальных при меньшей сомкнутости полога. При сомкнутости полога 0,6-1,0 уровень изменчивости повышенный, высокий и очень высокий $(26,5-$ $41,9 \%)$.

Результаты дисперсионного анализа показали, что доля влияния географического происхождения на диаметр ствола в подпологовых культурах составила 13,8 , а сомкнутости полога древостоя $-65,0 \%$.

Выводы. Рост кедра сибирского в подпологовых 50-летних культурах пригородной зоны Красноярска в основном зависит от сомкнутости полога древостоя, в меньшей степени - от географического происхождения.

Высота культур при сомкнутости полога 0,6-1,0 на $36,6 \%$ меньше, чем при сомкнутости $0,1-0,5$; прирост центрального побега за два последних года - на $41,1 \%$; диаметр ствола - на $44,8 \%$; диаметр кроны - на 21,7\%; количество боковых ветвей - на $16,2 \%$.

Лучшими показателями роста отличаются деревья алтайского и читинского происхождений. Рекомендуется в исследованных культурах провести рубки ухода с установлением сомкнутости полога не более 0,5 .

\section{Библиографические ссылки}

Anuchin, N.P. (1983). Density of planting and its definition. Forestry, 8, 42-45 (in Russian).

Babakin, A.S., \& Zolotukhin, F.M. (1976). On the relationship of closeness, of fullness and density of tree stands // Increase of forests productivity and improvement of forestry, 83, 22-24. Moscow: Moscow Institute of Forestry (in Russian).

Bratilova, N.P. (2005). Variability of Cedar at plantation cultures of South Central Siberia depending on mold diversity seedlings. Krasnoyarsk: SibSU (in Russian).

Bratilova, N.P. Matveeva, R. N., Butorova, O.F., \& Scherba, J.E. (2015). Pine cedar siberian growth of different geographic origin in the age of 17-46 // Proceeding of the Forestry Academy of Sciences of Ukraine, 13, 59-63 (in Russian).
Bryncev, V.A., \& Kozhenkova, A.A. (2016). Growth of different with provenances Hamburg Siberian pine when introduced in Moscow region // Gardening, seed growing, introduction of woody plants: materials of the XXI international Scientific Conference, 11-14. Krasnoyarsk: SibSU (in Russian).

Demakov, J.P., \& Safin, M.G. (2010). Influence of natural factors on the dynamics of growth of trees in Sphagnum Pine plantings // Forest ecosystems in a changing climate: biological productivity, monitoring and adaptation technologies, 122-125. http:/csfin.marstu.net/ publications.html.

Dospehov, B. A. (1979). Technique of field experiences (the basics of statistical processing of research results). Moscow: Kolos (in Russian).

Drozdov, I. I. (1978). Research of Cedar forest cultures in the Vladimir region // Scientific Works Moscow Institute of Forestry, 111, 116-118 (in Russian).

Drozdov, I. I., Kozhenkova, A.A., \& Belinsky, M.N. (2013). Pine cedar siberian reproduction in the Moscow suburbs // MSFU Bulletin. Forestry Bulletin, 3, 4-7.

Eremin, N.V., Karaseva, M.A., \& Karasev, V.N. (2010). Agronomic and physiological aspects of successful cultivation Pine cedar siberian in the Republic of Mari El. Forest. Ecology. Environmental management, 1, 29-38 (in Russian).

Ermolenko, P. M., \& Ovchinnikova, N.F. (1996). Cedar growth in cultures under the canopy Birch forest in the Dark pine belt of Western Sayana // Botanical researches in Siberia, 5, 40-42 (in Russian).

Zalesov, S. V. (1988). The role of the culture of the under the canopy in restoring Cedar Siberian planting // The problem of reforestation in the taiga zone of the USSR, pp. 85-87. Krasnoyarsk: Institute of Forest (in Russian).

Zemljanoi, A.I., Ilichev, Y.N., \& Tarakanov, V.V. (2010). Variability between clones of Cedar Siberian at elements of seed production, selection prospects // Conifers of the boreal area, 27, 77-82 (in Russian).

Kuznetsova, G. V. (1990). The growth and preservation of geographic cultures of Cedar Siberian and Cedar Korean in Krasnoyarsk region // The problem of Cedar: semenoshenie and reproduction, pp. 78-82. Tomsk: Tomsk researcher center (in Russian).

Kuznetsova, G.V. (2010). Growth, status and development of Cedar pines in geographic cultures South of Krasnoyarsk region // Conifers of the boreal area, 27, 102-107 (in Russian). 
Loskutov, R.I. (1971). Artificial Cedar Siberian restoration. Moscow: Forest industry (in Russian).

Mamaev, S.A. (1973). Forms of intraspecific variability of woody plants. Moscow: Science (in Russian).

Matveeva, R.N., Bratilova, N.P., \& Butorova, O.F. (2017). Growth and reproductive development of Pine Cedar Siberian of different geographic origin, with high density ordinary landing (green zona of Krasnoyarsk). Krasnoyarsk: SibGU (in Russian).

Protopopov, V.V. (1975). The extremely important role of dark pine forest. Novosibirsk: Science (in Russian).

Titov, E.V. (1990). The selection of plus trees Cedar Siberian in the mountainous Altai // Forestry, 2, 4244 (in Russian).

Titov, E.V. (2016). Selection of valuable genotypes of clones Cedar Siberian on grafting plantations // Conifers of the boreal area, 37, 284-289 (in Russian).

Salminen, H., Jalkanen, R. (2006). Modelling variation of needle density of Scots pine at high latitudes // Silva fenn, 40 (2), 183-194.

Von Mirko, L., Schuler, S., \& Wei-benbacher, L. (2008). Experiences with geographic cultures the FIR great (Abies grandis Lindl.) in Austria: suitability, productivity growth, variability.) // Centralbl. gesamte Forstw, 125 (3), 183-200.

\section{Ріст 50-річних піднаметових географічних культур кедра сибірського за різної зімкнутості намету деревостану в приміській зоні Красноярська}

\section{Р.Н. Матвеєва ${ }^{1}$, О.Ф. Буторова ${ }^{2}$, Е. В. Колосовський ${ }^{3}$}

Наведено відомості щодо росту кедра сибірського у лісових культурах під наметом деревостану залежно від географічного походження. Кедр сибірський, який відзначається цінними біоекологічними властивостями, потребує збереження і штучного

Матвеєва Рімма Нікітічна - доктор сільськогосподарських наук, професор кафедри селекції та озеленення. Сибірський державний університет науки і технологій имені академіка М.Ф. Решетньова, пр. Миру, 82, м. Красноярськ, 660049, Росія. Тел.: (391)227-58-09. E-mail: selekcia@ sibgtu.ru ORCID: https://orcid.org/0000-0002-3033-2036

Буторова Ольга Федорівна - доктор сільськогосподарських наук, професор кафедри селекції та озеленення. Сибірський державний університет науки і технологій имені академіка М.Ф. Решетньова, пр. Миру, 82, м. Красноярськ, 660049, Росія. Тел.: (391)227-58-09. E-mail: selekcia@ sibgtu.ru ORCID: https://orcid.org/0000-0002-3033-2036

Колосовський Едуард Вікторович - аспірант кафедри селекції та озеленения. Сибірський державний університет науки i технологій имені академіка М.Ф. Решетньова, пр. Миру, 82, м. Красноярськ, 660049, Росія. Тел.: (391)227-58-09. E-mail: selekcia@ sibgtu.ru лісовідновлення та лісорозведення у приміських зонах великих промислових центрів. 3 огляду на високу стійкість кедра сибірського при виростанні в групах і під наметом лісу, в приміській зоні Красноярська були створені географічні культури деревного виду на ділянці «Гірський-2» в Караульному лісництві Навчально-дослідного лісгоспу СибДУ. Культури створені в 1966 р. садінням 4-річних сіянців в площадки розміром $07 \times 0,7$ м (по 9 сіянців на майданчик) з відстанню між центрами майданчиків в 4 м. У лідируючих в кожному майданчику дерев визначали висоту, діаметр стовбура на висоті 1,3 м, діаметр крони, приріст центрального пагона, кількість бічних гілок на нижній живій мутовці і ін. Достовірність відмінностей визначали за t-критерієм. Визначали коефіцієнти кореляції $\mathrm{i}$ встановлювали наявність і тісноту зв'язку між досліджуваними показниками. Частку впливу географічного походження і зімкнутості намету на ріст культур визначали методом дисперсійного аналізу.

Узагальнено результати вивчення мінливості кедра сибірського шести географічних походжень: алтайське, бірюсінске, бурятське, кемеровське, томське, читинське, які ростуть під наметом берези повислої і сосни звичайної за зімкнутості намету деревостану від 0,1 до 1,0 . Встановлено, що в 50-річному віці культури досягли висоти 5,4-10,4 м, діаметра стовбура - 2,0-16,5 см. Культури, які ростуть за зімкнутості намету $0,1-0,5$, мали висоту на $36,6 \%$, діаметр стовбура - на 44,8 \% більші. Рівень мінливості показників - середній і високий. Приріст центрального пагона в культурах 49-50-річного віку склав 26,6-60,6 см. У культурах зі значним освітленням (зімкнутість намету $0,1-0,5$ ) цей показник перевищено на 41,1\% порівняно із деревами, які ростуть в затінених умовах (зімкнутість намету 0,6-1,0) за підвищеного, високого і дуже високого рівнів варіювання. Найбільшу кількість гілок у нижній живій мутовці (4,8 і 4,1 шт.) встановлено у дерев читинського, найменшу (3,2 і 2,3 шт.) - у дерев кемеровського походжень. Рівень варіювання показника підвищений в алтайському і бірюсінському варіантах; високий - в інших варіантах за меншої зімкнутості намету. За зімкнутості намету 0,6-1,0 рівень мінливості підвищений і високий $(26,5-41,9 \%)$. Відзначено, що більший вплив на біометричні показники лісових культур виявляе компактність намету $(65,0 \%)$. Частка впливу географічного походження на ріст кедра сибірського у культурах склала 13,8\%. Запропоновано проведення рубок догляду для зниження зімкнутості намету деревостану на рівні 0,5 . Актуальним завданням $€$ здійснення подальших досліджень у піднаметових культурах кедра сибірського після проведення рубок догляду.

Ключові слова: лісові культури; географічне походження; густота; мінливість; біометричні показники; Сибір. 


\section{Growth of geographic cultures of Siberian cedar for $\mathbf{5 0}$ years under the canopy with different logging density in the suburban area of Krasnoyarsk}

\section{R. Matveeva', O. Butorova², E. Kolosovsky ${ }^{3}$}

Information about the growth of Cedar Siberian culture under canopy of tree stands depending on the geographical origin are provided. Cedar Siberian, featuring a high nutritional and environmental qualities, needs to retain and artificial afforestation in suburban areas of major industrial centers. Taking into account high resilience of Cedar siberian in the groups and under the canopy, in the suburban area of Krasnoyarsk geographic culture were established under the canopy of tree stand on a plot «Gornii-2» in the Karaulny territory of the SibSU Experimental Forestry. It were created in 1966 year by landing 4-year-old seedlings in the sites sizes $07 \mathrm{~h} 0.7 \mathrm{~m}$ (9 seedlings in pad) between centers of sites $4 \mathrm{~m}$. In each site among the leader trees it was determined height, trunk diameter at a height of $1.3 \mathrm{~m}$, diameter koruna, growth of Central escape, number of

Rimma Matveeva - Doctor of Agricultural Sciences, Professor of the Department of breeding and planting SibSU, Reshetnev Siberian State University of Science and Technology Krasnoyarsk, Russian Federation

Olga Butorova - Doctor of Agricultural Sciences, Professor of the Department of breeding and planting SibSU, Reshetnev Siberian State University of Science and Technology Krasnoyarsk, Russian Federation

Eduard Kolosovsky - graduate student of Agricultural Sciences, Professor of the Department of breeding and planting SibSU, Reshetnev Siberian State University of Science and Technology Krasnoyarsk, Russian Federation lateral branches on the bottom of the live whorl, etc. The reliability differences determined by t-test. Correlation coefficients and presence and the closeness links between the studied variables were determined. The part of impact of geographical origin and the cramped canopy on the growth of the culture was define by the method of variance analysis. The paper summarizes the results of a study of the variability of six geographical origins Cedar siberian: Altay, Birjusinsky, Butyat, Kemerovsk, Tomsk, Chita, planted under a canopy of birch and Scots pine in cramped canopy tree stand from 0.1 to 1.0 . It has been established that the 50 -yearold culture reached a height of 5.4-10.4 m, diameter barrel $-16.5-2.0 \mathrm{~cm}$. Culture growing in cramped canopy $0.1-0.5$, had height at $36.6 \%$, trunk diameter-at $44.8 \%$ more. The level of variability- average and high. Increase Central escape in cultures of 49-50 years of age amounted to $26.6 \mathrm{~cm}-60.6$. In cultures with large lighting (0.1-0.5 canopy cover) exceeded this figure is $41.1 \%$, than in trees growing in shaded conditions (tree canopy 0.6-1.0) at elevated, high and very high levels of variation. The largest number of branches in the lower live whorl (4.8 and 4.1 PCs.) trees had Chita, smallest (3.2 and 2.3 PCs.) - trees Kemerovo origin. The level of variation indicator increased in Altai and Birjusinskom options; high in the rest with less cramped canopy. The level variability is increased and higher (26.5-41.9\%) when cramped canopy 0.61.0. It is noted that the greater influence on biometrics indicators has cramped canopy tree crops $(65.0 \%)$. The share of influence of geographical origin amounted to $13.8 \%$. It is proposed to conduct thinning to reduce the influence of canopy forest stand. Further research is planned in cultures of Cedar Siberian under canopy after thinning conducting.

Key words: forest cultures; geographical origin; density; variability; biometric indices; Siberia. 